\title{
A Simplified Relation Between Hot Layer Height and Opening Mass Flow
}

\author{
NILS JOHANSSON \& PATRICK VAN HEES \\ Department of Fire Safety Engineering and Systems Safety \\ Lund University, P.O. Box 118, SE-221 00 Lund, Sweden, Telephone: +46 462227360
}

\begin{abstract}
The mass flow of air through an opening in a well-mixed compartment fire can be calculated with a simple expression. Similar simple models are lacking for the stratified pre-flashover case. Usually an advanced computer model is required to calculate the mass flow through an opening in a pre-flashover compartment fire. However, two equations for the opening mass flow through an opening are presented and evaluated in this paper.

The presented equations are predominantly valid for temperatures above $200^{\circ} \mathrm{C}$ and predictions with the equations are shown to be within $10 \%$ of results from computer simulations and experimental measurements. The equations can also be combined with existing plume models in order to give an estimate of the hot layer height in a compartment fire with a predefined heat release rate.
\end{abstract}

KEYWORDS: fire dynamics, mass flow, zone model, hot layer height

\section{NOMENCLATURE LISTNING}

\begin{tabular}{llll}
$A_{o}$ & area of opening $\left(\mathrm{m}^{2}\right)$ & $\dot{Q}$ & heat release rate $(\mathrm{kW})$ \\
$A_{w}$ & area in contact with hot gases $\left(\mathrm{m}^{2}\right)$ & $\dot{Q}_{\mathrm{c}}$ & convective part of heat release rate $(\mathrm{kW})$ \\
$c_{p}$ & specific heat $(\mathrm{kJ} /(\mathrm{kg} \mathrm{K}))$ & $T_{a}$ & ambient temperature $(\mathrm{K})$ \\
$C_{d}$ & flow coefficent & $T_{g}$ & gas temperature $(\mathrm{K})$ \\
$D$ & $H_{D} / H_{o}$ & $t$ & time $(\mathrm{s})$ \\
$g$ & gravitational constant $\left(\mathrm{m} / \mathrm{s}^{2}\right)$ & $v_{g}$ & hot gas velocity $(\mathrm{m} / \mathrm{s})$ \\
$H_{D}$ & height of hot layer $(\mathrm{m})$ & $W$ & opening width $(\mathrm{m})$ \\
$H_{N}$ & height to neutral plane $(\mathrm{m})$ & $z$ & height of hot layer $(\mathrm{m})$ \\
$H_{o}$ & opening height $(\mathrm{m})$ & $z_{0} \quad$ height of virtual origin of fire plume $(\mathrm{m})$ \\
$h$ & heat transfer coefficient $\left(\mathrm{W} / \mathrm{m}^{2} \mathrm{k}\right)$ & Greek & \\
$k$ & constant & $\rho_{\text {a }}$ ambient gas density $\left(\mathrm{kg} / \mathrm{m}^{3}\right)$ \\
$k \rho c$ & Thermal inertia $\left(\mathrm{W}^{2} \mathrm{~s} / \mathrm{m}^{4} \mathrm{~K}^{2}\right)$ & $\rho_{\mathrm{g}}$ hot gas density $\left(\mathrm{kg} / \mathrm{m}^{3}\right)$ \\
$\dot{m}_{a}$ & mass flow rate of ambient air $(\mathrm{kg} / \mathrm{s})$ & subscripts \\
$\dot{m}_{f}$ & mass flow from fuel $(\mathrm{kg} / \mathrm{s})$ & $a$ & indicates ambient proporty \\
$\dot{m}_{g}$ & mass flow rate of hot gases $(\mathrm{kg} / \mathrm{s})$ & $g$ & indicates hot gas proporty \\
$\dot{m}_{p}$ & plume mass flow $(\mathrm{kg} / \mathrm{s})$ & 0 & vent opening \\
$N$ & $H_{N} / H_{o}$ & \multicolumn{2}{l}{}
\end{tabular}

\section{INTRODUCTION}

Pre-flashover fires are usually described as the stratified case or the two-zone model [1]. This stage in fire development is characterized by having two distinct layers or zones: one upper layer consisting of hot gases and one lower layer consisting of cooler ambient air (see Fig. 1). At flashover there will be a transition from the stratified stage to a well-mixed stage the so-called post-flashover fire. The maximum mass flow of air through an opening in a post-flashover compartment fire can be calculated with the following simple expression.

$\dot{m}=k \cdot A_{o} \sqrt{H_{o}}$

$A_{0} \sqrt{H_{o}}$ is commonly referred as the ventilation factor and was first recognised by Kawagoe [2] to be proportional to the air flow through openings. Where $A_{0}$ is the opening area, $H_{o}$ is the opening height and $k$ is a constant that have been found to vary between 0.4 and 0.6 [3] but is usually assigned to be $0.5[1,4]$. 
Equation 1 is valid for the well-mixed case and when the hot gas temperature is exceeding $300^{\circ} \mathrm{C}$, which is definitely the case for fully developed post-flashover fires. However, there is no similar simple expression for calculating the mass flow entering or leaving a pre-flashover fire. Quintiere and Wang have recently presented some expressions based on numerical studies $[5,6]$ which have shown to give good precitions of vent flows. These are based on a point source assumption and requires knowledge of the gas temperature. The latter results in the expressions not beeing applicable for engineering purposes in the same manner as Eq. 1. It would therefore be desirable to develop a expression similar to Eq. 1 for the pre-flashover fire. That kind of expression would be useful in fire safety design of buildings or in fire investigations in order to get a first estimate before any more complex and more time consuming efforts or calculations are made. More specifically, it could be used to get an estimate of the hot layer height with the help of a mass balance and existing plume models. This would be valuable since, to the knowledge of the authors, no such simple method exists.

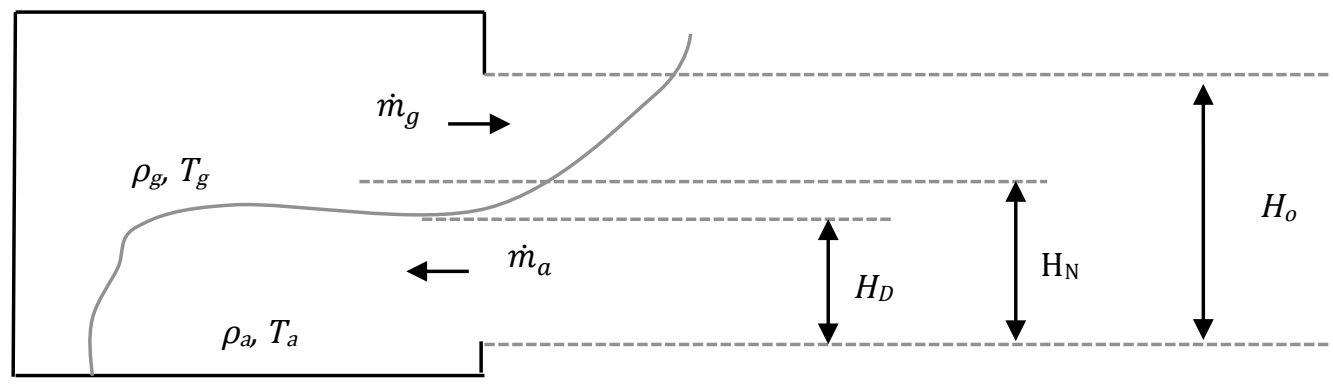

Fig. 1. The stratified case (picture reproduced from Enclosure Fire Dynamics [1]).

Fig. 1 illustrates the two-zone model, which has been found to give a good estimation of the conditions within a small or medium sized compartment (e.g. residental rooms, offices, or small industrial units) in a pre-flashover fire [1]. The basic assumption of the two-zone model is that the compartment can be divided into two distinctly different zones or layers. The interface between the two layers is located at the height $H_{D}$ above the floor. This height is referred to the height of thermal discontinuity [3] or the hot layer height [1]. The neutral plane, $H_{N}$, is defined as the height above a given reference (e.g. the floor) where the pressure difference is zero. The upper and lower layers are assumed to have a uniform temperatures in Kelvin, $T_{g}$ and $T_{a}$, and densities, $\rho_{g}$ and $\rho_{a}$. There will be an inflow of gases, $\dot{m}_{a}$, from the sill to $H_{N}$ and an outflow of gases, $\dot{m}_{g}$, from $H_{N}$ to the soffit $H_{O}$. The two-zone assumption is predominantly valid when the compartment length/width and width/height relation is less than 3 together with a compartment width/height relation of at least 0.4 [7]. The hot layer will in most cases be situated at a height of between 0 and $60 \%$ of $H_{o}$ above the sill $[3,8]$ and the neutral plane will be located above $H_{D}$.

\section{THEORY}

For the horizontal flow through a doorway or window (as illustrated in Fig. 1) will the height to the neutral plane, hot layer height and mass flow depend on each other. There are no analytical solutions available for these; instead it is necessary to perform iterations of these variables with the help of mathematical expression for the mass flows $\left(\dot{m}_{a}\right.$ and $\left.\dot{m}_{g}\right)$.

The speed of the gases leaving the compartment, $v_{g}$, at a distance, $z$, from the neutral plane can be expressed in the following form with the help of Bernoulli's equation [1].

$v_{g}=\sqrt{2 \cdot g \cdot z \cdot\left(\frac{\rho_{a}}{\rho_{g}}-1\right)}$

The mass flow leaving the compartment can be calculated by integrating over the opening width from the neutral plane to the opening soffit. This results in the following expression for $\dot{m}_{g}[1]$ :

$\dot{m}_{g}=\frac{2}{3} C_{d} \cdot W \cdot \rho_{a} \sqrt{2 \cdot g \cdot T_{a} / T_{g} \cdot\left(1-T_{a} / T_{g}\right)}\left(H_{o}-H_{N}\right)^{3 / 2}$ 
Where $C_{d}$ is the flow coefficient and $W$ is the width of the door. The flow coefficient has been found to be approximately 0.68 for the inflow and 0.73 for the outflow [9], but is commonly assumed to be 0.7 for both in- and outflow [1]. The mass flow of ambient air entering the compartment can be calculated by integrating over the opening width from the neutral plane to the opening sill. This integration results in the following expression for $\dot{m}_{a}$.

$\dot{m}_{a}=\frac{2}{3} C_{d} \cdot W \cdot \rho_{a} \sqrt{2 \cdot g \cdot\left(1-T_{a} / T_{g}\right)}\left(H_{N}-H_{D}\right)^{1 / 2}\left(H_{N}+\frac{1}{2} H_{D}\right)$

A complete description of how Eq. 3 and 4 are derived can be found in e.g. Enclosure Fire Dynamics [1] and the mass flow in and out of the openings is discussed in several textbooks in the field [8, 10]. Equations 3 and 4 have been shown to give good predictions compared to experiments $[11,12]$. For a stationary burning fire there will be a mass balance in the compartment.

$\dot{m}_{a}+\dot{m}_{f}=\dot{m}_{g}$

The mass flow from the fuel, $\dot{m}_{f}$, will in most cases be in the order of a couple of percent or less of $\dot{m}_{a}$. Consequently, it can be assumed that:

$\dot{m}_{a}=\dot{m}_{g}$

With this assumption Eq. 3 and 4 can be used and the following expression for the dependence of $H_{N}$ and $H_{D}$ can be derived.

$\sqrt{\rho_{g}}\left(H_{o}-H_{N}\right)^{3 / 2}=\sqrt{\rho_{a}}\left(H_{N}-H_{D}\right)^{1 / 2}\left(H_{N}+\frac{1}{2} H_{D}\right)$

Rockett [3] simplified Eq. 5 even further by introducing the following dimensionless variables:

$N=H_{N} / H_{o}$

$D=H_{D} / H_{o}$

This will results in the following equation:

$\left(\frac{1-N}{N}\right)^{3}=\left(1-\frac{D}{N}\right)\left(1+\frac{D}{2 N}\right)^{2} \frac{T_{g}}{T_{a}}$

The relationship between $D$ and $N$ in Eq. 6 can be found via iteration for certain values of $T_{g} / T_{a}$. This relationship has been presented by Rockett [3] and is also shown in Fig. 2.

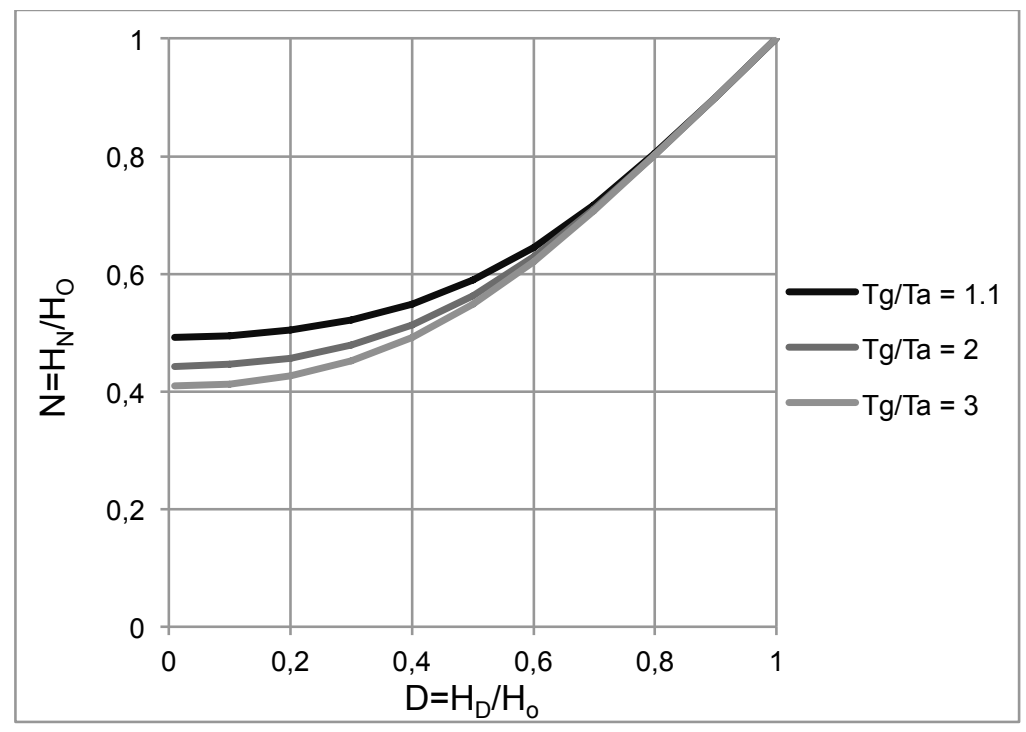

Fig. 2. Interdependence of $N, D$ and $T_{g} / T_{a}$, reproduced from Rockett [3]. 
It can be seen in Fig. 2 that $N$ will be rather independent of $\mathrm{T}_{\mathrm{g}} / \mathrm{T}_{\mathrm{a}}$ when $D>0.7$.

\section{A NEW RELATIONSHIP FOR OPENING MASS FLOW IN PRE-FLASHOVER FIRES}

In order to study how $D$ relates to the mass flow in the opening, further iteration for additional values of $T_{g} / T_{a}$ have been conducted at Lund University. The relationship between $\dot{m}_{g}$ and $D$ for different temperatures has been derived with Eq. 3 and the data presented in Fig. 2. This relationship is illustrated in Fig. 3 where the y-axis is a dimensionless expression of the mass flow.

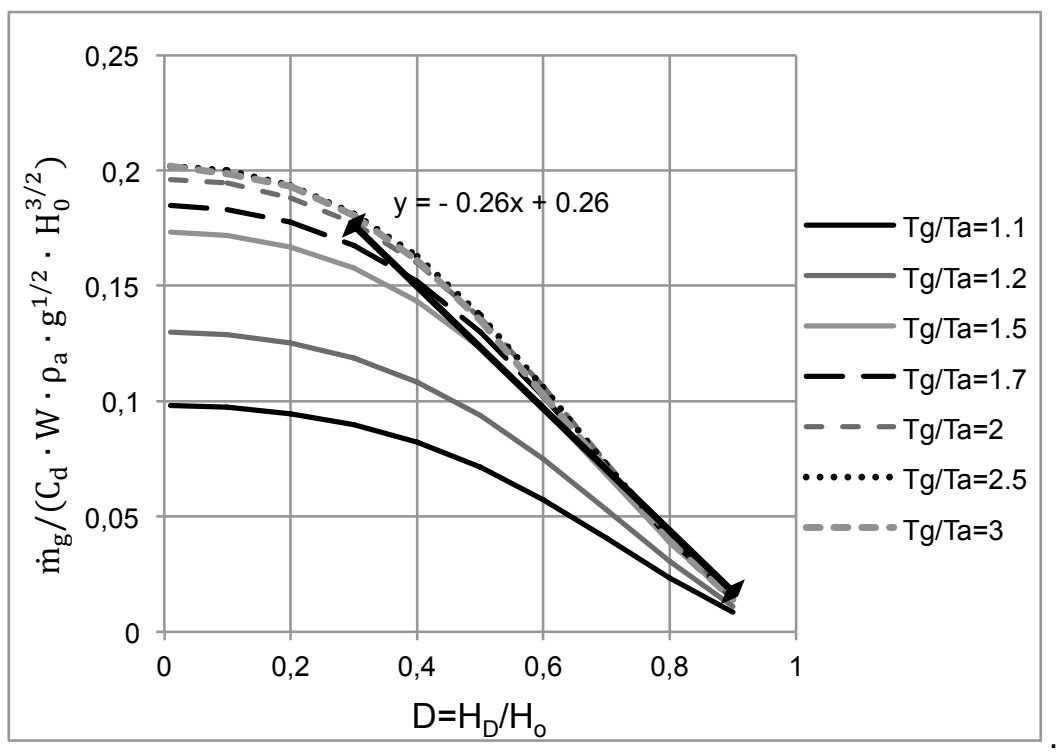

Fig. 3. A dimensionless mass flow as a function of hot layer height and temperature for $D>0.3$.

Fig. 3 illustrates that the mass flow will increase when $D$ decreases, e.g. as the hot layer descends. It is also clear that the mass flow will be rather linear and independent of $T_{g} / T_{a}$ when $T_{g} / T_{a}>1.7$ and $D>0.3$. With the help of a linear regression analysis it is possible to retrieve a simple approximate expression for the mass flow in this range (see Fig. 3), which yields in the following equation:

$\dot{m}_{g} /\left(C_{d} \cdot W \cdot \rho_{a} \cdot g^{1 / 2} \cdot H_{o}{ }^{3 / 2}\right)=0.26(1-D)$

Equation 7 can be rewritten into the following equation:

$\dot{m}_{g}=0.26 \cdot C_{d} \cdot W \cdot \rho_{a} \cdot g^{1 / 2} \cdot H_{o}^{3 / 2}(1-D)$

The regression fit in Fig. 3 is optimized for $T_{g} / T_{a}=1.7$ and the coefficient of determination $\left(\mathrm{R}^{2}\right)$ is slightly more than 0.99 , which is considered to be very good. The regression line was optimized for $T_{g} / T_{a}=1.7$ because it is considered to correspond to a typical pre-flashover temperature and it also gives a fairly good fit to the curves for $T_{g} / T_{a} \geq 1.5$ as can be seen in Fig 3. Equation 8 is considered to be valid for the stratified case $(D>0.3)$ and when the hot layer temperature is above roughly $200^{\circ} \mathrm{C}$. If standard values for $C_{d}=0.7, g=9.81 \mathrm{~m} / \mathrm{s}^{2}$ and $\rho_{a}=1.2 \mathrm{~kg} / \mathrm{m}^{3}$ are used will the constant in Eq. 8 be 0.684 and it can be rewritten as follows.

$\dot{m}_{g}=0.684 \cdot A_{o} \cdot H_{o}{ }^{1 / 2}(1-D)$

The mass flow for $D<0.3$ can be described with another linear expression (see Fig. 4). 


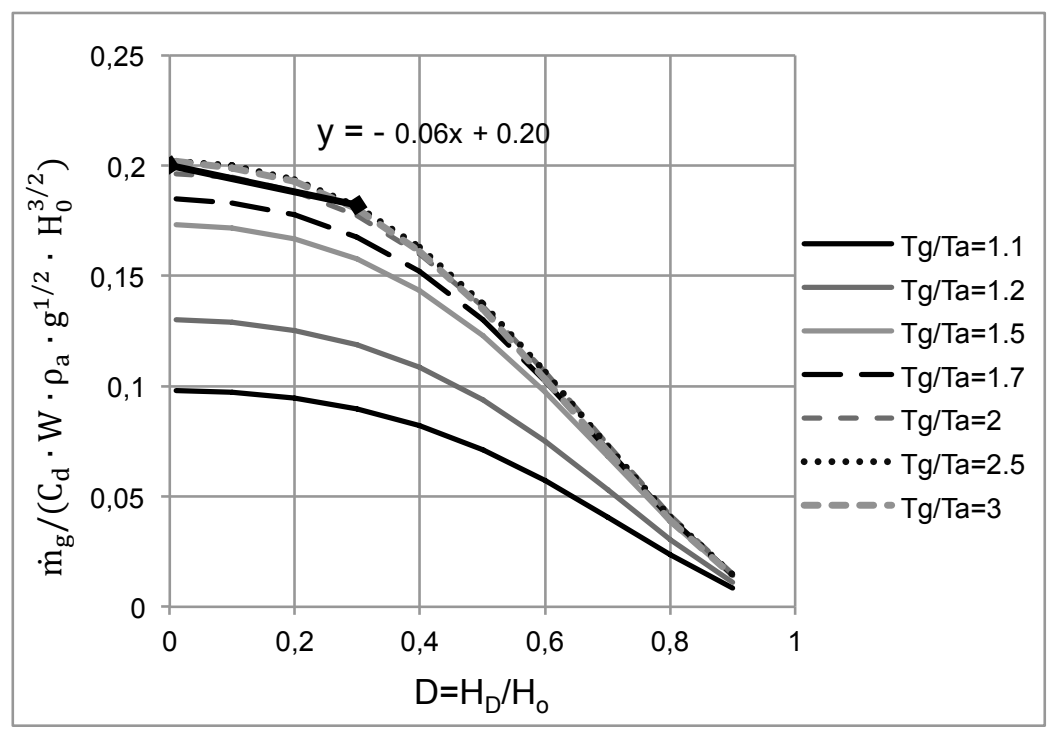

Fig. 4. A dimensionless mass flow as a function of hot layer height and temperature for $D<0.3$.

Using the linear expression for $\mathrm{D}<0.3$, according to Fig. 4 , yields in the following equation, which is derived with the standard values for $C_{d}, g$ and $\rho_{a}$ presented above.

$\dot{m}_{g}=0.53 \cdot A_{o} \cdot H_{o}{ }^{1 / 2}(1-0.3 \cdot D)$

Equation 10 is similar to Eq. 1 but Eq. 10 is valid for a interval of $D$. Equation 1 is valid for temperatures above $300^{\circ} \mathrm{C}$ [1] $\left(T_{g} / T_{a}>2.5\right)$ and as the hot layer descends to the floor, i.e. $D$ approaches 0 , will Eq. 10 and Eq. 1 give almost the same result.

Equations 9 and 10 are expressions that represent the theoretical relationship in Eq. 6, but the linear approximation introduces an error that is important to quantify. This error is presented in Fig. 5 as the differance between the calcuated mass flows with Eq. 9 and 10 and the mass flows given in Fig. 3, expressed in percentage, for a range of different temperature ratios.

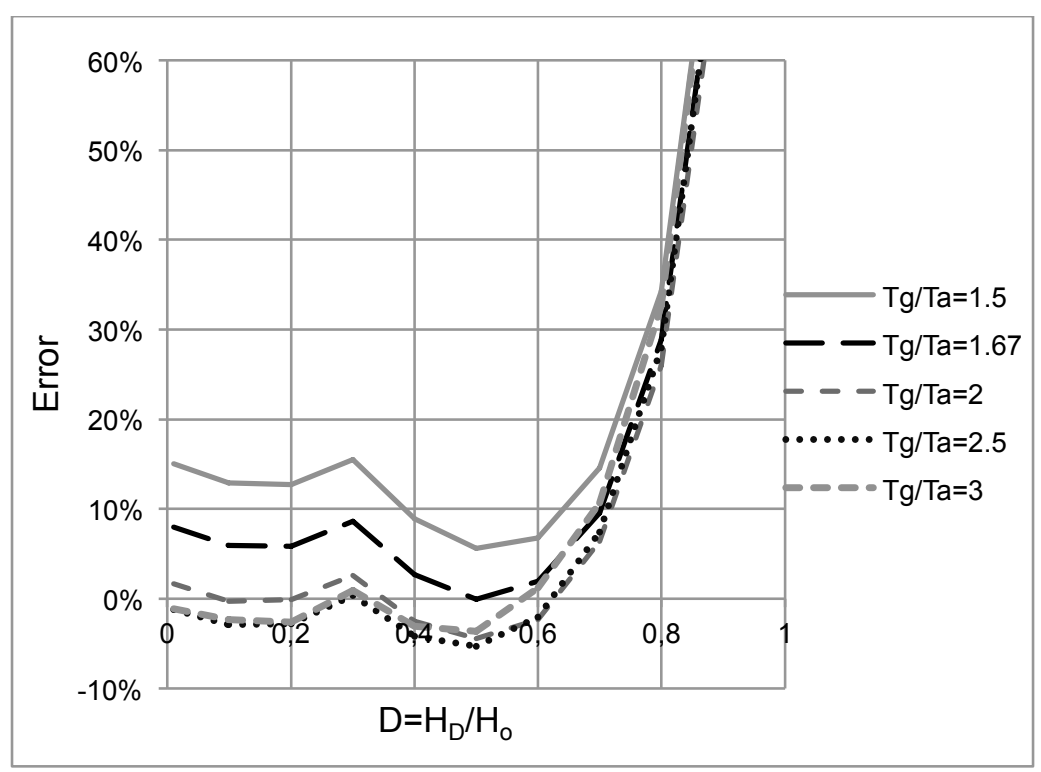

Fig. 5. The error of Eq. 9 and 10 compared to the theoretical relations, expressed in percentage. 
It is clear from Fig. 5 that the error in Eq. 9 for temperatures above $170^{\circ} \mathrm{C}\left(T_{g} / T_{a}>1.5\right)$ is less than $10 \%$ in the interval $0.4<D<0.65$. For temperatures above $220^{\circ} \mathrm{C}\left(T_{g} / T_{a}>1.67\right)$ will the error in Eq. 9 and 10 be less than $10 \%$ compared to the theoretical relations when $D<0.7$. The error increases rapidly for $D>0.7$ since the absolute values are low.

Equations 9 and 10 are expressions that have been derived from theory based on several assumptions and approximate curve fits. The two-zone approximation holds several assumptions [1,13] but has been shown to give good estimates of hot layer temperatures and heights [14]. Nevertheless, in order to determine the usability of the derived expressions it is considered necessary to conduct a evaluation.

\section{EVALUATION}

The focus of the evaulation is on Eq. 9 because it applies to the interval $D<0.7$ and $D>0.3$ in which the practical application of the equations is considered to lie. The evaluation is conduted by investigating how well predictions with Eq. 9 corresponds with more advanced calculation methods and experimental results from stationary pre-flashover fires. Three different sources of data have been used in the evaulation:

- Data from simulations in the two-zone model CFAST [15].

- Data from simulations in the CFD model FDS [16].

- Data from actual experiments performed by Steckler et al. [11].

The simulated and measured hot layer heights $\left(H_{D}\right)$ have been used in Eq. 9 to derive a mass flow that in turn is compared to a simulated or measured mass flow. No specific preferences have been made when choosing the compartment geometry and heat release rate other than giving a reasonable range of a typical stationary pre-flashover scenario.

\section{Simulation data from CFAST}

CFAST is a two-zone fire model developed at NIST [15]. CFAST is used to calculate smoke spread and temperature throughout compartments in a building during a fire. The compartments can range from about $1 \mathrm{~m}^{3}$ to large spaces on the order of $1000 \mathrm{~m}^{3}$ [15]. CFAST typically over-predicts hot layer temperatures and hot layer depths slightly, but the predictions are mostly within 10-20\% of the experimental measurements [17].

Nine simulations have been performed in CFAST6.2 where the heat release rate (HRR), room size and opening size have been varied (see Table 1). The wall and ceiling material consisted of $0.15 \mathrm{~m}$ thick concrete and the Heskestad plume correlation [19] was used in all simulations. The mass flow exiting the room in CFAST have been compared to the mass flow calculated with Eq. 9. The ratio between the calculated mass flow with Eq. 9 and the calculated mass flow with CFAST is provided in Table 1.

Table 1. Data from simulations in CFAST compared to $\dot{m}$ calculated with Eq. 9.

\begin{tabular}{|c|c|c|c|c|c|c|c|}
\hline $\begin{array}{l}\text { HRR } \\
(\mathrm{kW})\end{array}$ & $\begin{array}{l}\text { Room size } \\
\left(\mathbf{m}^{3}\right)\end{array}$ & $\begin{array}{l}\text { Opening } \\
\text { size }\left(H_{o} \times W\right) \\
\left(\mathrm{m}^{2}\right)\end{array}$ & $\begin{array}{l}H_{D} \text { from } \\
\text { CFAST } \\
(\mathrm{m})\end{array}$ & $T_{g} / T_{a}$ & $\begin{array}{l}\dot{m} \text { calculated } \\
\text { with CFAST } \\
(\mathrm{kg} / \mathrm{s})\end{array}$ & $\begin{array}{l}\dot{m} \text { predict } \\
\text { ed with eq. } \\
9(\mathrm{~kg} / \mathrm{s})\end{array}$ & Ratio \\
\hline 200 & $2.4 \times 3.6 \times 2.4$ & $2 \times 0.9$ & 1.01 & 1.45 & 0.85 & 0.87 & 1.02 \\
\hline 300 & $2.4 \times 3.6 \times 2.4$ & $2 \times 0.9$ & 0.97 & 1.61 & 0.94 & 0.90 & 0.96 \\
\hline 400 & $2.4 \times 3.6 \times 2.4$ & $2 \times 0.9$ & 0.93 & 1.76 & 1.01 & 0.94 & 0.93 \\
\hline 500 & $2.4 \times 3.6 \times 2.4$ & $2 \times 0.9$ & 0.88 & 1.89 & 1.07 & 0.98 & 0.91 \\
\hline 600 & $2.4 \times 3.6 \times 2.4$ & $2 \times 0.9$ & 0.83 & 2.01 & 1.12 & 1.02 & 0.91 \\
\hline 700 & $2.4 \times 3.6 \times 2.4$ & $2 \times 0.9$ & 0.78 & 2.12 & 1.16 & 1.07 & 0.92 \\
\hline 400 & $4 \times 4 \times 4$ & $2 \times 0.9$ & 0.91 & 1.60 & 0.98 & 0.95 & 0.97 \\
\hline 400 & $4 \times 4 \times 4$ & $3 \times 0.9$ & 1.55 & 1.48 & 1.57 & 1.55 & 0.99 \\
\hline 800 & $4 \times 4 \times 4$ & $3 \times 0.9$ & 1.43 & 1.78 & 1.86 & 1.68 & 0.90 \\
\hline
\end{tabular}


Equation 9 predicted the mass flow within 10\% compared to CFAST according to Table 1, although it would be expected that the difference would be larger for the cases where $T_{g} / T_{a}<1.6$, at least when comparing to Fig. 5. It was not unexpected that predictions gave a good agreement with CFAST because the fundamental assumptions and underlying equations are equivalent in the two methods.

\section{Simulation data from FDS}

FDS is a computational fluid dynamics (CFD) model for fire-driven fluid flows. The Navier-Stokes equations are solved numerically in FDS [16]. FDS has, just like CFAST, been shown to give predictions of hot layer depth and temperatures that fall within the bounds of the experimental uncertainty [20].

Seven simulations have been performed in FDS5 where the heat release rate, room size and opening size have been varied (see Table 2). The wall and ceiling consisted of $0.10 \mathrm{~m}$ thick concrete. The mass flows exiting the room in FDS have been compared to the mass flow calculated with Eq. 9. The ratio between the predicted mass flow with Eq. 9 and the calculated mass flow with FDS is provided in Table 2. The hot layer height and average hot layer temperature have been recorded in the opening with the help of the "layer height" and "upper temperature" functions in FDS, which are based on the two-layer reduction method $[16,21]$.

Table 2. Data from simulations in FDS compared to $\dot{m}$ calculated with Eq. 9.

\begin{tabular}{|c|c|c|c|c|c|c|c|}
\hline $\begin{array}{l}\text { HRR } \\
(\mathbf{k W})\end{array}$ & $\begin{array}{l}\text { Room } \\
\text { size }\left(\mathbf{m}^{3}\right)\end{array}$ & $\begin{array}{l}\text { Opening size } \\
\left(H_{o} \times W\right) \quad\left(\mathbf{m}^{2}\right)\end{array}$ & $\begin{array}{l}H_{D} \text { from } \\
\text { FDS (m) }\end{array}$ & $T_{g} / T_{a}$ & $\begin{array}{l}\dot{m} \text { calculated } \\
\text { with FDS } \\
(\mathrm{kg} / \mathrm{s})\end{array}$ & $\begin{array}{l}\dot{m} \text { predicted } \\
\text { with eq. } 9 \\
(\mathrm{~kg} / \mathrm{s})\end{array}$ & Ratio \\
\hline 720 & $3 \times 3 \times 3$ & $2 \times 1$ & 0.76 & 1.89 & 1.20 & 1.20 & 1.00 \\
\hline 540 & $3 \times 3 \times 3$ & $2 \times 1$ & 0.85 & 1.71 & 1.15 & 1.12 & 0.97 \\
\hline 360 & $3 \times 3 \times 3$ & $2 \times 1$ & 0.93 & 1.57 & 1.03 & 1.04 & 1.01 \\
\hline 450 & $3 \times 3 \times 3$ & $2 \times 1$ & 0.89 & 1.66 & 1.10 & 1.08 & 0.98 \\
\hline 450 & $3 \times 3 \times 3$ & $1.8 \times 0.8$ & 0.76 & 1.77 & 0.83 & 0.77 & 0.92 \\
\hline 540 & $3 \times 3 \times 3$ & $2 \times 1$ & 0.82 & 1.60 & 1.16 & 1.15 & 0.99 \\
\hline 720 & $3 \times 3 \times 3$ & $2 \times 1$ & 0.83 & 1.72 & 1.23 & 1.14 & 0.93 \\
\hline
\end{tabular}

There are fundamental differences between the calculation procedure of FDS and the assumptions of Eq. 9, but still were the predictions of mass flow with Eq. 9 within $8 \%$ of the mass flow calculated with FDS.

\section{Data from experiments by Steckler et al.}

Eleven experiments from a well-know experimental series performed at the National Bureau of Standards by Steckler et al [11] were used in this evaluation. The experiments have been performed in a square room with the side $2.8 \mathrm{~m}$ and $2.18 \mathrm{~m}$ height. The mass flow in the opening was calculated from velocity measurements with bi-directional probes and temperature measurements with thermocouples. The hot layer interface was estimated with the help of temperature measurements. Steckler et al [11] varied the fire size and location in the room, but in this analysis only the experiments with the fire source in the centre of the room and with a door opening were used.

Table 3. Experimental data compared to $\dot{m}$ calculated with Eq. 9.

\begin{tabular}{|c|c|c|c|c|c|c|}
\hline $\begin{array}{l}\text { HRR } \\
(\mathbf{k W}) \\
\end{array}$ & $\begin{array}{l}\text { Opening size } \\
\left(H_{o} \times W\right)\left(\mathbf{m}^{2}\right)\end{array}$ & $\begin{array}{l}\text { Measured } \\
H_{D}(\mathrm{~m}) \\
\end{array}$ & $T_{g} / T_{a}$ & $\begin{array}{l}\text { Measured } \\
\dot{m}(\mathrm{~kg} / \mathrm{s}) \\
\end{array}$ & $\begin{array}{l}\dot{m} \text { predicted } \\
\text { with eq. } 9(\mathrm{~kg} / \mathrm{s})\end{array}$ & Ratio \\
\hline 63 & $1.83 \times 0.24$ & 0.57 & 1.55 & 0.25 & 0.28 & 1.10 \\
\hline 63 & $1.83 \times 0.36$ & 0.74 & 1.45 & 0.36 & 0.35 & 0.99 \\
\hline 63 & $1.83 \times 0.49$ & 0.86 & 1.40 & 0.46 & 0.44 & 0.96 \\
\hline
\end{tabular}




\begin{tabular}{|l|l|l|l|l|l|r|}
\hline 63 & $1.83 \times 0.49$ & 0.86 & 1.43 & 0.47 & 0.45 & 0.97 \\
\hline 63 & $1.83 \times 0.62$ & 0.91 & 1.36 & 0.52 & 0.52 & 1.00 \\
\hline 63 & $1.83 \times 0.74$ & 0.97 & 1.33 & 0.56 & 0.57 & 1.02 \\
\hline 63 & $1.83 \times 0.74$ & 0.91 & 1.33 & 0.56 & 0.61 & 1.09 \\
\hline 63 & $1.83 \times 0.74$ & 1.03 & 1.34 & 0.62 & 0.57 & 0.91 \\
\hline 63 & $1.83 \times 0.74$ & 1.03 & 1.34 & 0.61 & 0.55 & 0.92 \\
\hline 63 & $1.83 \times 0.86$ & 1.03 & 1.31 & 0.62 & 0.63 & 1.02 \\
\hline 63 & $1.83 \times 0.99$ & 1.09 & 1.29 & 0.68 & 0.68 & 1.00 \\
\hline 105 & $1.83 \times 0.74$ & 0.97 & 1.48 & 0.64 & 0.56 & 0.90 \\
\hline 158 & $1.83 \times 0.74$ & 0.91 & 1.67 & 0.69 & 0.60 & 0.87 \\
\hline
\end{tabular}

Despite that the HRR and temperatures were rather low in the experiments, Eq. 9 predicted the mass flow within 13\% compared to the experimental data. As can be seen in Table 3, there was a variation in the experimental measurements. Some of the experiments had the same experimental setup but there was still a difference of more than $10 \%$ in the hot layer height, which gives an indication of the uncertainties in the experiments.

\section{Summary of evalution}

A graphical presentation of the performed evaluation is presented in Fig. 6.

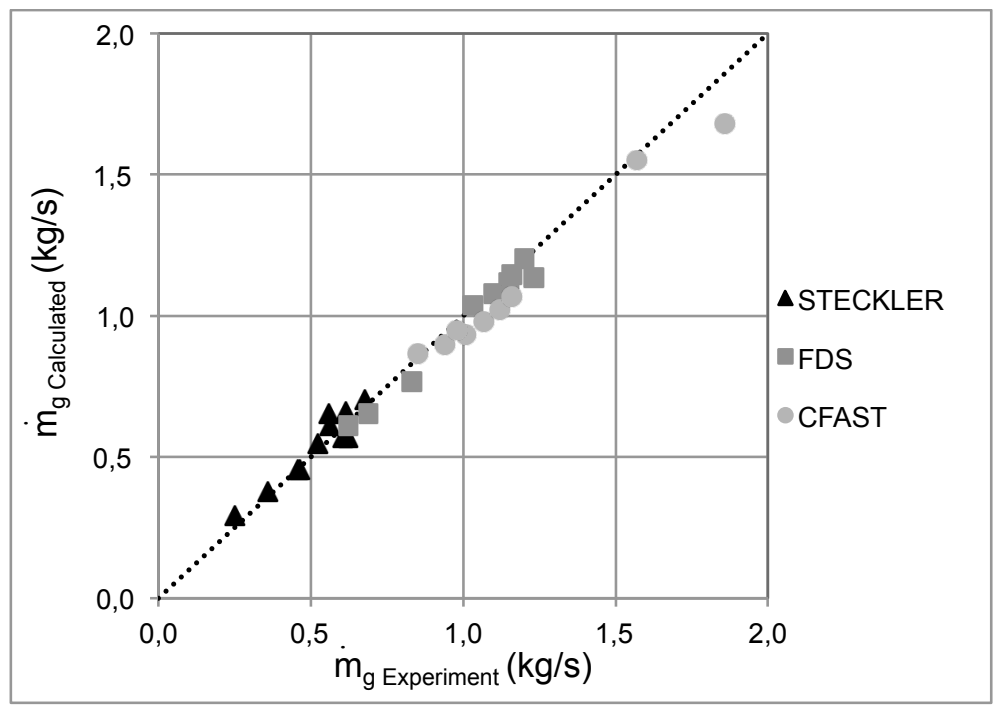

Fig. 6. The calculated mass flow with Eq. 9 compared to data from CFAST, FDS and Steckler et al. The doted line represents a perfect agreement.

The predictions with Eq. 9 were within $13 \%$ of the simulation and experimental results and for the majority of the studied scenarios it was less than 5\%. In an evaluation study of six experimental series condcuted by NRC [18] the relative expanded uncertainty (95\% confidence interval) for estimates of hot layer depth ranged from $6 \%$ to $35 \%$. In the light of this are the predictions with Eq. 9 considered to be good.

\section{PRACTICAL USE OF THE RELATIONSHIP}

The obvious application of Eq. 9 is to use it to estimate the mass flow of gases leaving a compartment in a case when the hot layer height is known. However, it could also be used in estimating the hot layer height or hot layer temperature. 


\section{Hot layer height}

There are currently no simple engineering tool to estimate the hot layer height in a compartment fire. When a fire with a constant heat release rate has formed a stationary hot layer there will be a mass balance between the plume mass flow entering the hot layer, $\dot{m}_{p}$, and the mass flow leaving the compartment, $\dot{m}_{g}$. Several empirical correlations for plume mass flow are available in the literature [1] and they are applicable for different situations. The hot layer will probably be located about one or two meters above the fire source and the flames will be close to the hot layer. Consequently is a strong plume model $[1,19]$ the best choice in this demonstration. The Heskestad plume correlation (Eq. 11) [19] is a strong plume model that is considered suitable.

$\dot{m}_{p}=0.071 \cdot \dot{Q}_{c}^{1 / 3} \cdot\left(z-z_{0}\right)^{5 / 3}+1.92 \cdot 10^{-3} \cdot \dot{Q}_{c}$

Where $\dot{Q}_{c}$ is the convective part of the heat release rate, $z_{0}$ is the virtual origin and $z$ is the position of the hot layer height (denoted $H_{D}$ in previous sections). The heat release is in most engineering applications provided by the designer when the design fire is chosen. With Eq. 9 or 10 and 11 a hot layer height, $H_{D}$, can be found with a iterative process, i..e. by guessing values of $H_{D}$ and calculating $\dot{m}_{p}$ with Eq, 11 and $\dot{m}_{g}$ with Eq. 9 or 10 until $\dot{m}_{p}=\dot{m}_{g}$. In Fig. 7, calculated values of $H_{D}$ in the previously mentioned CFAST and FDS simulations (x-axis) are compared to $H_{D}$ estimated with Eq. 9 and 11 (y-axis).

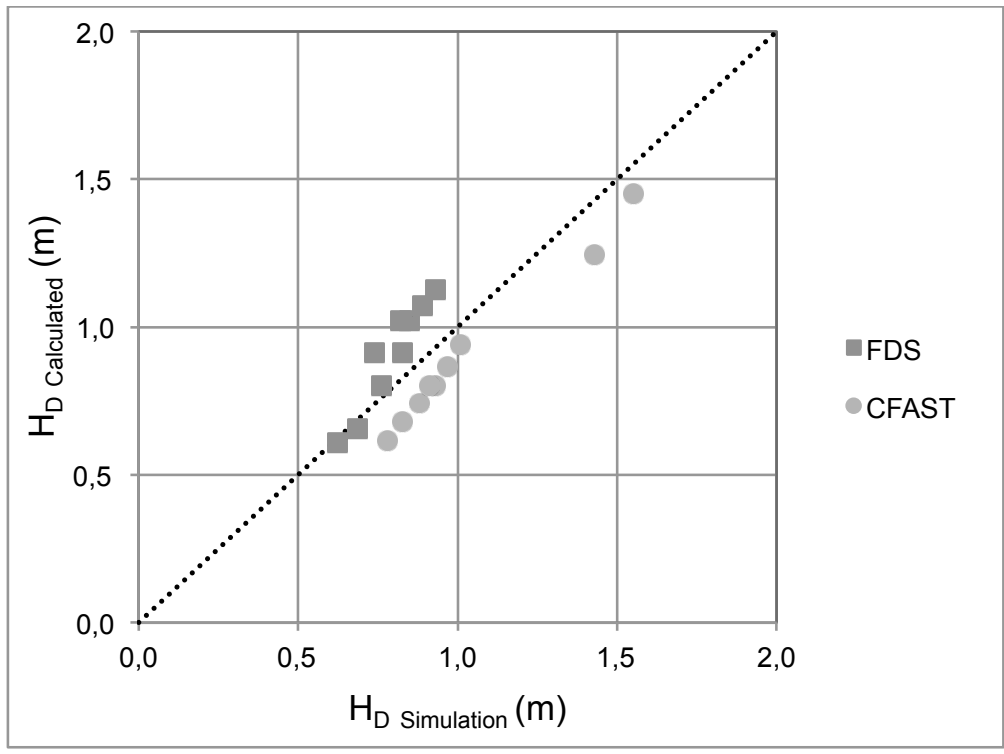

Fig. 7. The calculated hot layer height $\left(H_{D}\right)$ with Eq. 9 and 10 compared to data from CFAST and FDS. The doted line represents a perfect agreement.

The calculated $H_{D}$ is within $20 \%$ for both of the CFAST and FDS calculations. The difference is increased compared to the mass flow calculations (see Fig. 6), this is due to the introduction of the empirical plume model (Eq. 11).

\section{Hot layer temperature}

With a known hot layer height, a hot layer temperature can be derived with a simplified energy balance (see Eq. 12) that accounts for the convective energy flux out through an opening and the heat loss to the compartment boundaries [1].

$\dot{Q}=\dot{m}_{g} \cdot c_{p} \cdot\left(T_{g}-T_{a}\right)+h \cdot A_{w} \cdot\left(T_{g}-T_{a}\right)$ 
Where $T_{g}$ is the hot layer temperature, $h$ is the heat transfer coefficient and $A_{w}$ is the boundaries in contact with the hot layer. The heat losses due to radiation out through the opening and the energy stored in the gases are ignored because the terms in Eq. 12 can be said to be to be dominating [1]. Equation 12 can be rewritten as an expression for temperature increase.

$\Delta T=\frac{\dot{Q}}{\dot{m}_{g} \cdot c_{p}+h \cdot A_{w}}$

A more detailed explanation of this simple heat balance is available on several textbooks $[1,8,10]$. No example calculations are given here for the hot layer temperature. The heat balance can be solved with the help of Eq. 9 and a suitable plume model, e.g. as in Fig. 7, and the hot layer temperature in a compartment with known boundary materials can be calculated. The simplified heat balance holds numerous simplifications [1] and it will probably give a rough estimate of $\Delta T$. Nevertheless such a simplified approach can be valuable for engineering estimates and can also reduced the calculation time considerably when numerous calculations are performed.

In conclusion, the derived equations can be used to perform rather simple calculations of both the hot layer height and hot layer temperature; these two properties are commonly studied in the fire safety design of buildings in order to evaluate heat and smoke exposure to occupants [22]. Consequently, it is considered that the presented equations can be of great use.

\section{DISCUSSION AND CONCLUSIONS}

For fully developed (post-flashover) fires there is a simple expression for calculating the mass flow through an opening and to the knowledge of the authors there are no similar simple expression for pre-flashover fires. However, two equations that fill this gap are presented in this paper. An advanced computer model is usually required to calculate the mass flow through an opening in a pre-flashover compartment fire. But, the simple expressions presented can be used to give a good estimate of the mass flow when the hot layer height is known. The expressions are approximations associated with some limitations, but allow for faster calculations and are believed to be a useful and powerful tool when studying multiple fire scenarios in a fire safety design.

The presented work is based on a simplified theory, which assumes a uniform temperature in a hot layer. This assumption has previously been shown to give good agreement with experimental measurements and the presented equations are considered to be useful for this situation. The equations should work reasonably well for $D$ ranging from 0 to 0.7 and $T_{g} / T_{a}>1.7$ because the error is, according to Fig. 5 , less than $10 \%$ in this interval. The error in the predictions will increase with lower temperatures (see Fig. 5). But, according to the conducted evaluation it seems like the equations will give reasonable results even for temperature ratios as low as $T_{g} / T_{a}=1.5$.

Both data from computer simulations and experiments have been used in a evaluation. The two computer models used are based on assumptions and simplifications of varying degrees but both have been found to predict hot layer heights with good accuracy in previous studies [17, 20]. The experimental data is also associated with uncertainties due to e.g. measurement errors and systematic errors. The predictions with Eq. 9 are within $13 \%$ of the simulation and experimental results and for the majority of the studied scenarios it is less than $5 \%$. This is considered to be an almost negligible difference in regard to the uncertainties that can exist in both computer models and experimental measurements [18]. Further validation studies of the equations are however recommended as well as comparsion to other types of expressions like those presented by Quintiere and Wang [5,6].

It has been shown in the paper that Eq. 9 could be used together with a simple plume model in order to give a rough estimate of the hot layer height in a compartment fire with a predefined heat release rate. However, plume models include several simplifications and empirical constants, which means that uncertainties will be added to the uncertainties already existing in Eq. 9. It is not considered to be good to integrate a plume model expression with Eq. 9 since it can be difficult to grasp the combined uncertainties. Also, the choice of plume model should be a delicate work where the fire and compartment size should be considered. 


\section{ACKNOWLEDGEMENT}

The authors would like to thank Professor Ulf Wikström, Luleå University of Technology, Sweden, for valuable comments on this work.

\section{REFERENCES}

[1] Karlsson, B. \& Quintiere, J.G., Enclosure Fire Dynamics, CRC Press, 1999.

[2] Kawagoe, K., "Fire Behaviour in Rooms", Building Research Insitute, Report No. 27, Japan, 1958.

[3] Rockett, J.A., Fire Induced Gas Flow in an Enclosure, (1976) Combustion Science and Technology 12: 4-6, pp. 165-175, http://dx.doi.org/10.1080/00102207608946717.

[4] ISO 16737:2012, "Fire Safety Engineering - Requirments governing algebraic equations - Vent flows," International Organization for Standardization , 2012.

[5] Wang, L. \& Quintiere, J.G., (2009) An analysis of compartment fire doorway flows, Fire Safety Journal 44, pp. 718-731, http://dx.doi.org/10.1016/j.firesaf.2009.02.001.

[6] Quintiere, J.G. \& Wang, L. (2009) A general formula for the prediction of vent flows, Fire Safety Journal 44, pp. 789-792, http://dx.doi.org/10.1016/j.firesaf.2009.03.012.

[7] ISO/WD 13390, "Fire Safety Engineering -, Subsystem 1: Initiation and development of fire and fire effluents," International Organisation for Standardization, 1995.

[8] Quintere, J.G., Fundamentals of Fire Phenomena, Wiley, 2006.

[9] Steckler, K.D., Baum, H.R. \& Quinitiere, J.G., "Fire induced flows through room openings - flow coefficents," Twentieth Symposium (International) on Combustion, The Combustion Institute, 1985, pp. 1591-1600, http://dx.doi.org/10.1016/S0082-0784(85)80654-8.

[10] Drysdale, D., An Introduction to Fire Dynamics, third edition, Wiley, 2011, http://dx.doi.org/10.1002/9781119975465.

[11] Steckler, K.D., Quintiere, J.G. \& Rinkinen, W.J., "Flow induced by fire in a compartment", Nineteenth Symposium (International) on Combustion, The Combustion Institute, 1982, pp. 913920, http://dx.doi.org/10.1016/S0082-0784(82)80267-1.

[12] Steckler, K.D., Quintiere, J.G. \& Rinkinen, W.J., "Flow induced by fire in a compartment," National Bureau of Standards, Center of Fire Research, NBSIR 82-2520, Washington, 1982.

[13] Quintiere, J. G., (1989) Fundamentals of Enclosure Fire Zone Models, Journal of Fire Protection Engineering 1: 3, pp. 99-119, http://dx.doi.org/10.1177/104239158900100302.

[14] Najafi, D., Jolgar, F., \& Dreisbach, J., "Verification and Validation of Selected Fire Models for Nuclear Power Plant Applications, Volume 1: Main report," U.S. Nuclear Regulatory Commission, NUREG-1824, Washington, DC, 2007.

[15] Peacock, R.D., Jones, W.W., Reneke, P.A. \& Forney, G.P., "CFAST - Consolidate Model of Fire Growth and Smoke Transport (Version 6), User's guide," National Institute of Standards and Technology, NIST SP 1041, Gaithersburg, MD,,2008. 
[16] McGrattan, K., Hostikka, S., Floyd, J., Baum, H., Rehm, R., Mell, W. \& McDermott, R., "Fire Dynamics Simulator (Version 5) Technical Reference Guide Volume 1: Mathematical Model,“ National Institute of Standards and Technology Gaithersburg, NIST SP 1018-5, Gaithersburg, MD, 2010.

[17] Peacock, R.D., McGrattan, K., Klein, B., Jones, W.W. \& Reneke, P.A., “CFAST - Consolidate Model of Fire Growth and Smoke Transport (Version 6), Software Development and Model Evaluation Guide," National Institute of Standards and Technology, NIST SP 1086, Gaithersburg, MD, 2008.

[18] Hamins, A. \& McGrattan, K., "Verification \& Validation of Selected, Volime 2: Experimental Uncertainty", NUREG-1824, U.S. Nuclear Regulatory Comission, 2007.

[19] Heskestad, G., "Fire Plumes, Flame Heights and Air Entrainment," The SPPE Handbook of Fire Protection Engineering ( $4^{\text {th }}$ ed)," National Fire Protection Association, Quincy, MA, 2008.

[20] McGrattan, K., McDermott, R., Hostikka, S. \& Floyd, J., "Fire Dynamics Simulator (Version 5) Technical Reference Guide Volume 3: Validation,“ NIST SP 1018-5, National Institute of Standards and Technology, Gaithersburg, MD, 2010.

[21] Janssens, M.L. \& Tran, H.C. (1992) Data Reduction of Room Tests for Zone Model Validation, Journal of Fire Science 10, pp. 528-555, http://dx.doi.org/10.1177/073490419201000604.

[22] Purser, D., "Assesment of Hazards to Occupants from Smoke, Toxic Gases and Heat", The SPPE Handbook of Fire Protection Engineering ( $4^{\text {th }} \mathrm{ed}$ ), National Fire Protection Association, Quincy, MA, 2008. 